Boise State University

ScholarWorks

Geosciences Faculty Publications and

Presentations

Department of Geosciences

$2-2020$

\title{
Co-Eruptive Tremor from Bogoslof Volcano: Seismic Wavefield Composition at Regional Distances
}

\author{
Matthew M. Haney \\ Alaska Volcano Obervatory \\ David Fee \\ University of Alaska Fairbanks \\ Kathleen F. McKee \\ Carnegie Institution for Science \\ John J. Lyons \\ Alaska Volcano Observatory \\ Robin S. Matoza \\ University of California, Santa Barbara
}

See next page for additional authors

This document was originally published in Bulletin of Volcanology by Springer Nature. This is a U.S. government work and not under copyright protection in the U.S.; foreign copyright protection may apply. doi: 10.1007/ s00445-019-1347-0 


\section{Authors}

Matthew M. Haney, David Fee, Kathleen F. McKee, John J. Lyons, Robin S. Matoza, Aaron G. Wech, Gabrielle Tepp, Cheryl Searcy, and T. Dylan Mikesell 


\title{
Co-eruptive tremor from Bogoslof volcano: seismic wavefield composition at regional distances
}

\author{
Matthew M. Haney ${ }^{1}$ (D) David Fee $^{2}$ (D) Kathleen F. McKee ${ }^{3}$ (D) John J. Lyons ${ }^{1}$ (D) Robin S. Matoza $^{4}$ (D) \\ Aaron G. Wech ${ }^{1}$ (D) $\cdot$ Gabrielle Tepp ${ }^{1}$ (D) Cheryl Searcy $^{1}$ (D) $\cdot$ T. Dylan Mikesell ${ }^{5}$ (D)
}

Received: 10 April 2019 / Accepted: 11 December 2019

(C) This is a U.S. government work and not under copyright protection in the U.S.; foreign copyright protection may apply 2020

\begin{abstract}
We analyze seismic tremor recorded during eruptive activity over the course of the 2016-2017 eruption of Bogoslof volcano, Alaska. Only regional recordings of the tremor wavefield exist for Bogoslof, making it a challenge to place the recordings in context with other eruptions that are normally captured by local seismic data. We apply a technique of time-frequency polarization analysis to three-component seismic data to reveal the wavefield composition of Bogoslof eruption tremor. We find that at regional distances, the tremor is dominated by P-waves in the band from 1.5 to $10 \mathrm{~Hz}$. Using this information, along with an enriched Bogoslof earthquake catalog, we obtain estimates of average reduced displacement $\left(D_{\mathrm{R}}\right)$ for eruption tremor during 25 of the 70 Bogoslof events. $D_{\mathrm{R}}$ reaches as high as approximately $40 \mathrm{~cm}^{2}$ for two of the major events, similar to other VEI 3 eruptions in Alaska. Overall, average reduced displacement displays a weak correlation to plume height during the first half of the 9-month-long eruption sequence, with a few notable exceptions. The two events with the highest $D_{\mathrm{R}}$ values also generated measurable eruption tremor at very-long-periods (VLP) between 0.05 and $0.15 \mathrm{~Hz}$.
\end{abstract}

Keywords Volcano monitoring $\cdot$ Volcanic tremor $\cdot$ Explosive volcanism

This paper constitutes part of a topical collection:

The 2016-17 shallow submarine eruption of Bogoslof volcano, Alaska Editorial responsibility: C. Waythomas; Special Issue Editor N. Fournier

Electronic supplementary material The online version of this article (https://doi.org/10.1007/s00445-019-1347-0) contains supplementary material, which is available to authorized users.

Matthew M. Haney

mhaney@usgs.gov

1 U.S. Geological Survey, Alaska Volcano Observatory, Anchorage, AK, USA

2 Alaska Volcano Observatory, University of Alaska Fairbanks, Geophysical Institute, Fairbanks, AK, USA

3 Department of Terrestrial Magnetism, Carnegie Institution for Science, Washington, D.C., USA

4 Department of Earth Science and Earth Research Institute, University of California, Santa Barbara, Santa Barbara, CA, USA

5 Environmental Seismology Lab, Department of Geosciences, Boise State University, Boise, ID, USA

\section{Introduction}

Volcanic tremor, especially eruption tremor (sustained seismicity during an eruption), is a ubiquitous seismic signal observed at volcanoes worldwide and its observation is of prime importance in real-time monitoring. As a signal, however, it defies conventional methods of seismic analysis which are commonly tailored to discrete, short duration $(<1 \mathrm{~min})$ events with clear body-wave P- and S-phase arrivals. Volcanic tremor is the seismic expression of a wide range of physical processes (Konstantinou and Schlindwein 2002). It can last from minutes to months (McNutt and Nishimura 2008) and, typically, neither the underlying process nor the seismic wave type comprising a particular tremor signal is known a priori. Eruption tremor forms a subset of volcanic tremor in which the process is broadly understood to be the eruption itself; however, different models have been proposed for eruption tremor without consensus. Due to its complexity and widespread use in monitoring, both non-eruptive and eruptive volcanic tremor remain an active area of research in volcano seismology (Chouet et al. 1997; Wegler and Seidl 1997; Konstantinou and Schlindwein 2002; Haney 2010; Chouet and Matoza 2013; Almendros et al. 2014; Kumagai et al. 2015). 
The 2016-2017 eruption of Bogoslof volcano was marked by a sequence of 70 explosive events typically producing minutes to tens of minutes of co-eruptive volcanic tremor on regional seismic stations situated on neighboring islands (Fig. 1). Eruptive activity extended over 8 months, commencing on December 12, 2016 and ending on August 30, 2017. The morphology of the volcano varied significantly over the course of the eruption (Waythomas et al. 2020), with individual eruptive events happening when the vent was either submarine or emergent subaerial (Fee et al. 2020). During some long-duration eruptive events, transitions occurred from a submarine to a subaerial vent, but most events began at vents that were shallow submarine $(<200 \mathrm{~m}$; Fee et al. 2020). The regional seismic stations were the closest seismometers to the volcano, and regional co-eruptive seismic tremor was a key observation signaling eruptive activity from Bogoslof (Wech et al. 2018). Overviews and further details of the eruption are provided in Coombs et al. (2018) and Coombs et al. (2019). During the eruption, the explosive events were caught in realtime by either Real-time Seismic Amplitude (RSAM), infrasound array detections (Lyons et al. 2020), or lightning alarms (Coombs et al. 2018). The RSAM alarm (Endo and Murray 1991) almost always activated during periods of intensifying tremor, as shown in Coombs et al. (2018). However, it sometimes triggered when volcanic earthquakes occurred closer and closer in time (Coombs et al., 2018). Thus, it was often the case that RSAM alarms were triggered by co-eruptive tremor, which itself is poorly understood.

While regional $(>20 \mathrm{~km}$ ) recordings of volcanic tremor were commonplace during the Bogoslof eruption, they are relatively understudied at volcanoes in general because of the preference for local $(<20 \mathrm{~km})$ recordings of volcano seismicity. Local seismic networks can facilitate eruption forecasts during the run-up to explosions, whereas regional stations can only be expected to detect the onset of eruptive activity. Limited shortterm forecasting is possible with regional seismic data for later events in an eruption sequence only once patterns are recognized, as was the case during the Bogoslof eruption (Coombs et al. 2018). Despite regional eruption tremor being understudied, it is often observed for eruptions in Alaska. Figure 2 shows seismograms, all at the same scale, of eruption tremor in the frequency band from 1 to $10 \mathrm{~Hz}$ from the Bogoslof (2016-2017), Okmok (2008), Kasatochi (2008), and Redoubt (2009) eruptions at regional distances between 90 and $155 \mathrm{~km}$. Both the Okmok and Redoubt eruptions were also recorded by local seismic stations; however, for Kasatochi, only regional recordings existed (similar to Bogoslof). Note that the seismograms for Bogoslof and Okmok are from the same station and at a similar distance from the volcano; thus, we can surmise that the Bogoslof eruption tremor was at a similar level as the strongest, initial tremor from the Okmok 2008 eruption. In all cases, these large eruptions generate continuous 1 to 10 $\mathrm{Hz}$ tremor signals between 0.1 and $0.2 \mu \mathrm{m}$ of displacement at ranges on the order of $100 \mathrm{~km}$ that can be clearly picked up on regional seismometers (Fig. 2).

Instrument sensitivity to regional tremor is particularly important in remote, volcanically active regions such as the Aleutian Islands. In a study analyzing the 2008 Kasatochi and 2006 Augustine eruptions, Prejean and Brodsky (2011) propose a force source model for high-frequency $(>0.5 \mathrm{~Hz})$ volcanic

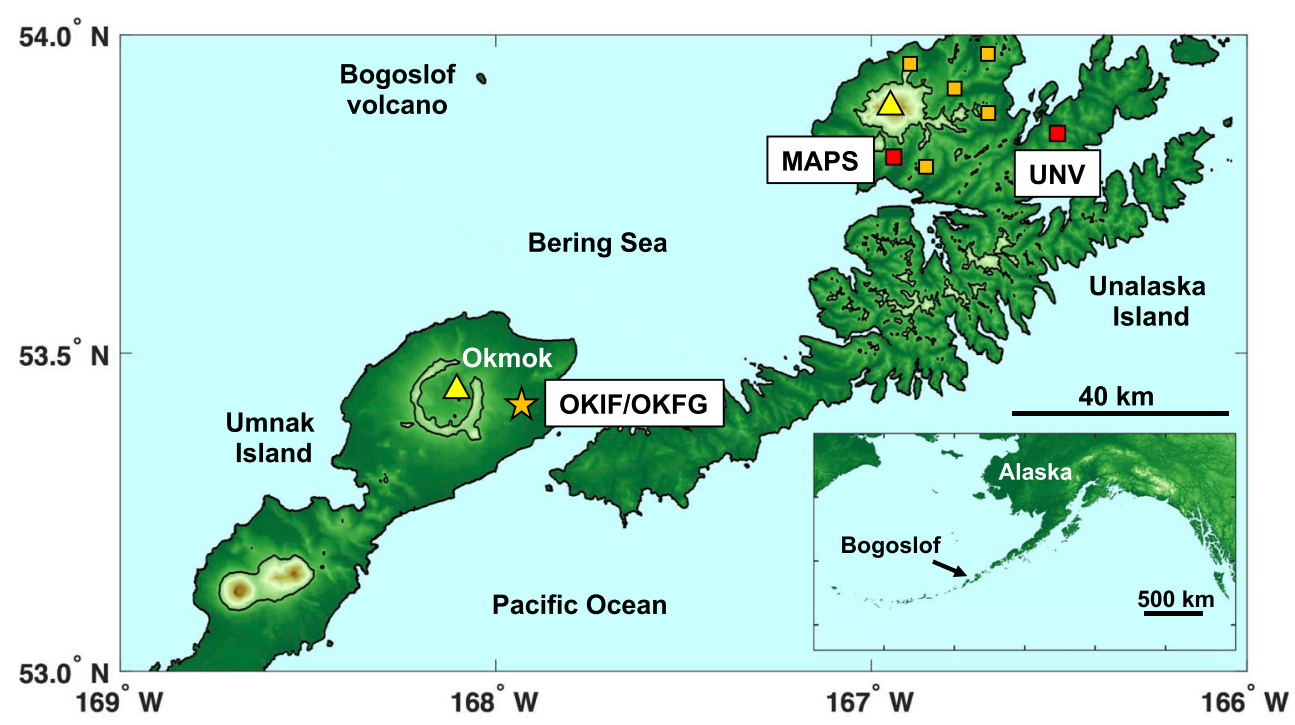

Fig. 1 Regional map of Bogoslof volcano and nearby Unalaska and Umnak Islands with primary broadband seismic stations MAPS and $\mathrm{UNV}$ used in this study shown as red squares. Another primary seismic station (OKFG) is closely located to a microphone array (OKIF) and indicated with an orange star. Orange squares are other broadband seismic

stations on Unalaska used for beamforming of low frequency tremor. Inset map shows the location of Bogoslof in the Aleutian Islands region. The primary seismic stations are at $58 \mathrm{~km}$ (OKFG), $73 \mathrm{~km}$ (MAPS), and $100 \mathrm{~km}$ (UNV) range from the volcano. Other historically active volcanoes are indicated by yellow triangles 
Fig. 2 Examples of regionally recorded volcanic tremor in the band from 1 to $10 \mathrm{~Hz}$ from eruptions in Alaska. All plots are shown at the same scale for comparison and the displays are intentionally clipped to maintain the scale. a Seismogram of an eruption at Bogoslof volcano from station on Unalaska Island at $100 \mathrm{~km}$ range. b Seismogram from same Unalaska Island station but of the 2008 eruption of Okmok 115 km away. An unrelated regional earthquake is labeled with its magnitude. $\mathbf{c}$ Regional recording of the 2008 Kasatochi eruption from a station $90 \mathrm{~km}$ from the volcano. Volcanic earthquakes exceeding M3.4 at Kasatochi also shown. d Two events from the 2009 Redoubt eruption as seen on a station $155 \mathrm{~km}$ away
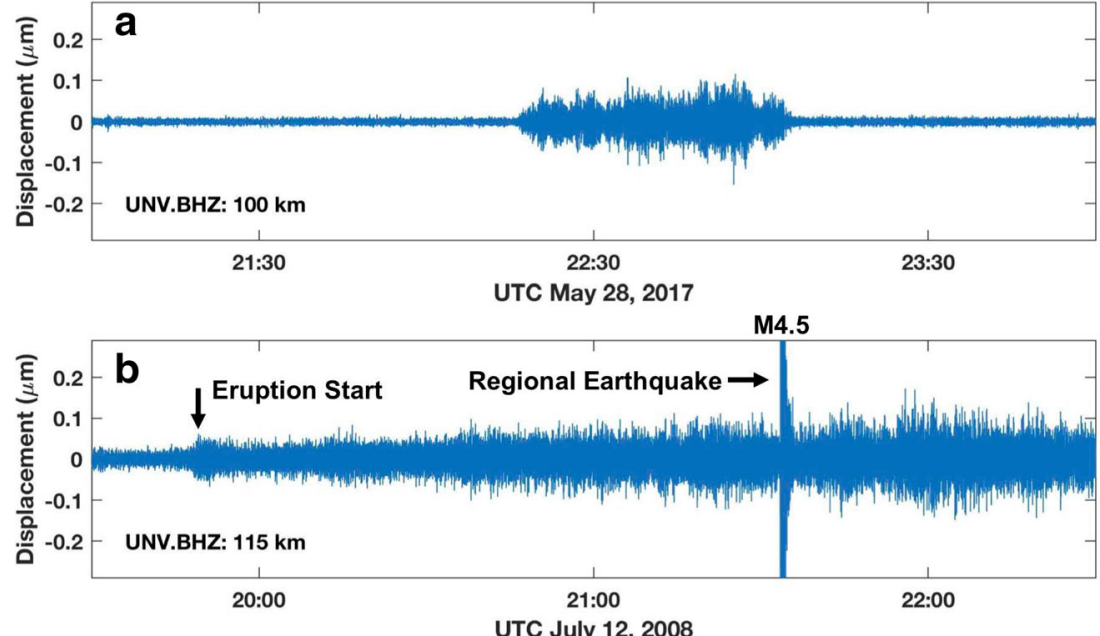

M3.4 M3.7 M4.2
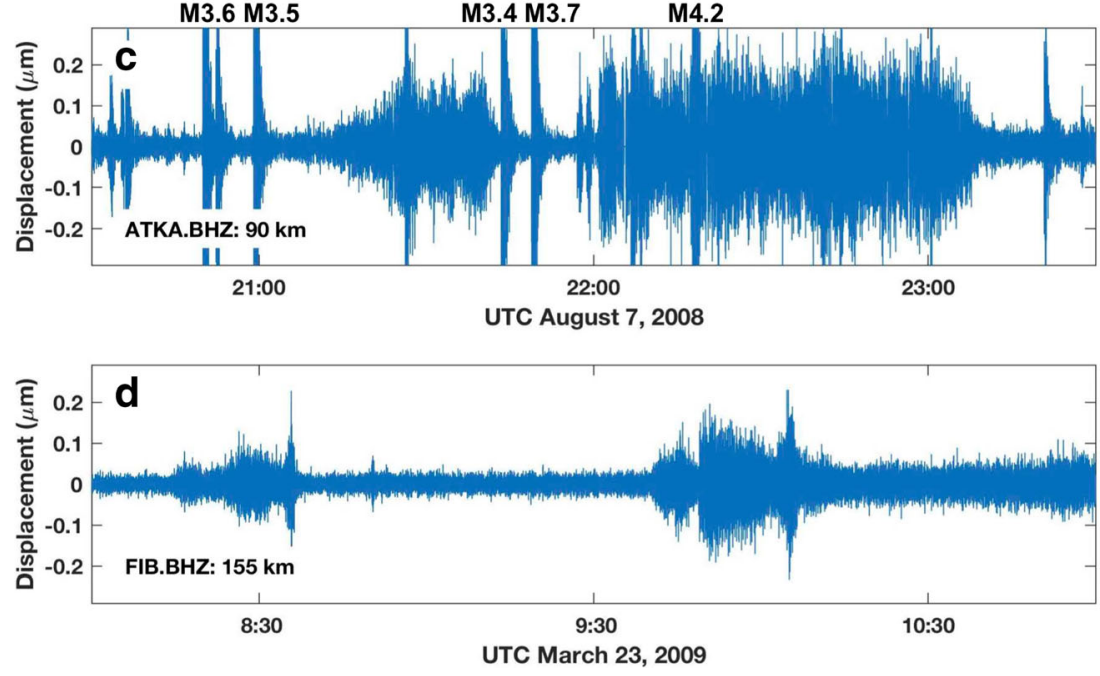

tremor recorded on regional stations and couple it to a model for plume height. They report regional volcanic tremor from the Kasatochi and Augustine eruptions as being primarily comprised of Rayleigh waves. Eruption tremor wavefields made up of surface waves make sense due to the shallow sourcing of eruptive activity, which can be expected to generate significant surface wave energy. Haney (2010) reports on low-frequency $(0.2-0.3 \mathrm{~Hz})$ eruptive tremor composed of surface waves during the 2008 Okmok eruption that registered on local seismic stations. Note that the wavefield composition of higher frequency Okmok eruption tremor, above $0.3 \mathrm{~Hz}$, was not determined by Haney (2010). Other discussions of regional volcanic tremor include a non-eruptive episode from Mount St. Helens analyzed by Denlinger and Moran (2014) that was clearly visible at stations beyond $100 \mathrm{~km}$ range. Matoza et al. (2018) show regional eruption tremor on seismometers out to approximately $250 \mathrm{~km}$ from Calbuco during its 2015 eruption. McNutt et al. (1991) also discuss volcanic tremor from the 1986 eruption of Pavlof volcano that was measured out to $160 \mathrm{~km}$.

Clearly, the presence of local stations diminishes the value of regional observations of volcanic tremor for real-time monitoring. But as noted by Prejean and Brodsky (2011), regional recordings can have value for subsequent analysis when local stations saturate or are dominated by seismicity not directly related to the eruption process, such as lahars. For the Bogoslof eruption, since the only recordings of eruption tremor were captured on distant seismometers, regional seismic data are of primary importance for gauging the nature and intensity of the eruption seismicity. Here, we make an initial attempt to uncover seismological aspects of the eruption tremor, beginning with an investigation of what type of seismic waves primarily constituted tremor signals observed regionally during the Bogoslof eruption. We then estimate the tremor intensity using reduced displacement (Aki and Koyanagi 1981), a standard measure of tremor size.

\section{Data and methods}

We analyze seismic data from stations located on Umnak and Unalaska Islands, the islands closest to Bogoslof where Okmok and Makushin volcanoes are located (Fig. 1). These 
data were used extensively for real-time monitoring of the 2016-2017 eruption and are also discussed in Wech et al. (2018), Fee et al. (2020), Tepp and Haney (2019), Tepp et al. (2020), and Searcy and Power (2020). The three seismic stations we utilize are all three-component, broadband seismometers with digital telemetry. Two of the stations, MAPS and OKFG, are Guralp-6TDs with a flat response between $30 \mathrm{~s}$ and $50 \mathrm{~Hz}$ and the other, UNV, is a Trillium 120 with a flat response between $120 \mathrm{~s}$ and $50 \mathrm{~Hz}$. All three seismometers sampled at $50 \mathrm{~Hz}$. We also use times of eruptive activity identified from an array of 4 microphones, named OKIF, which is located close to seismic station OKFG. We assume volcanic tremor recorded during these eruptive time periods is linked to the eruption process (i.e., eruption tremor). The catalog of eruptive times has previously been used by Wech et al. (2018) for the analysis of an enriched Bogoslof earthquake catalog. The catalog enrichment was accomplished through multichannel matched-filtering, using the manual, analystbased catalog for seed events. Details about the enriched catalog are given in Wech et al. (2018).

For three-component recordings of eruption tremor, we utilize a method for computing polarization attributes of the wavefield in the combined time-frequency domain. Previously, volcanic tremor has been analyzed with purely frequency domain (Chouet et al. 1997) or time-domain polarization analyses (Konstantinou and Schlindwein 2002; Ereditato and Luongo 1994); however, to our knowledge, time-frequency polarization analysis has not yet been applied to eruption tremor. Denlinger and Moran (2014) have performed a type of time-frequency polarization analysis on non-eruptive tremor during the 2004-2008 eruption of Mount St. Helens and inferred the tremor resulted from the drag of nearly solid magma along the conduit wall. The time bins Denlinger and Moran (2014) used were intentionally set to be fairly wide to maximize frequency resolution, and dense time-frequency plots were not shown. D'Auria et al. (2010) applied time-frequency polarization analysis in the wavelet domain to a long-period event and a Vulcanian explosion signal at Stromboli and showed how the method could separate seismic phases arriving within complex volcanic signals. Although time-frequency polarization analysis has not been extensively applied to volcanic tremor, the concept of measuring polarization in the combined time-frequency domain has been discussed previously by Paulssen et al. (1990) and Jones et al. (2016) within the context of earthquake signals. Diallo et al. (2005) have applied time-frequency polarization analysis to active source seismic data. The distinction between time, frequency, and time-frequency polarization analysis is important since polarization can be expected to vary strongly as a function of frequency (Neuberg and Pointer 2000), and the proper frequency binning is rarely known a priori. The method we describe below generalizes the Vidale (1986) time-domain method to the time-frequency domain by considering a single monochromatic time-domain signal. In the time-frequency domain, such a monochromatic signal would constitute a single pixel in the time-frequency plot.

The time-frequency polarization analysis begins by breaking the three-component seismic displacement time series into overlapping time windows. Throughout this study, we use time windows of 8 -s length and $90 \%$ overlap. For each timewindow, we smooth with a Hanning taper and then form the three-component cross-spectral matrix $S(\omega)$ :

$S(\omega)=\left[\begin{array}{lll}S_{\mathrm{ZZ}} & S_{\mathrm{NZ}}^{*} & S_{\mathrm{EZ}}^{*} \\ S_{\mathrm{NZ}} & S_{\mathrm{NN}} & S_{\mathrm{EN}}^{*} \\ S_{\mathrm{EZ}} & S_{\mathrm{EN}} & S_{\mathrm{EE}}\end{array}\right]$

where the subscripts indicate the two components used in each cross-spectrum and an asterisk represents complex conjugation. The cross-spectral power densities are computed using Welch's averaged, modified periodogram method (Welch 1967). The anti-symmetry of the imaginary parts of the offdiagonal components in Eq. (1) means $S(\omega)$ is a Hermitian matrix and its eigenvalues are all real, which is important for forming real-valued polarization parameters. The crossspectrum is equivalent to the Fourier transform of the crosscorrelation between the two components. The elements of the matrix along the main diagonal are real-valued, whereas the off-diagonal elements are in general complex-valued. We note that some eigenvalues of $S(\omega)$ may be zero in the case of pure modes, but this is unlikely to occur in practice. In fact, the elements along the main diagonal of Eq. (1) are the power spectral densities estimated for a single time window of the individual vertical and horizontal components. Soubestre et al. (2018) have used a similar M-by-M Hermitian matrix constructed from cross-spectra of $\mathrm{M}$ vertical component stations in a network to detect and locate tremor at volcanoes in Kamchatka, Russia.

After forming the cross-spectral matrix, we find its eigenvalues and eigenvectors and sort them by the size of the eigenvalues. As discussed in Vidale (1986), the phase of the complex-valued eigenvectors is initially arbitrary. We follow Vidale (1986) by finding, through a line search, the phase which maximizes the real part of the eigenvector associated with the largest eigenvalue, called the dominant eigenvector. Once that phase has been applied, we find the incidence angle (Fig. 3) of the dominant eigenvector. The most straightforward way to find the incidence angle $\phi$, with the vertical $(Z)$, north $(N)$, and east $(E)$ components of the real part of the dominant eigenvector indicated by $\left(v_{\mathrm{Z}}, v_{\mathrm{N}}, v_{\mathrm{E}}\right)$, is

$$
\phi=\tan ^{-1}\left(\frac{1}{v_{\mathrm{Z}}} \sqrt{v_{\mathrm{N}}^{2}+v_{\mathrm{E}}^{2}}\right)
$$




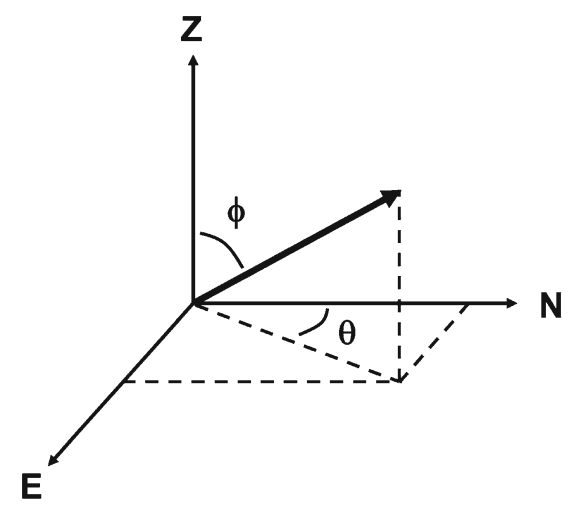

Fig. 3 Definition of incidence angle $\phi$ and azimuth $\theta$ computed from time-frequency polarization analysis of three-component seismograms. Both quantities are only resolved within $180^{\circ}$, as in Vidale (1986) for time-domain polarization analysis. The $180^{\circ}$ ambiguity of seismic particle motion can in principle be resolved in the case of elliptical motion, but cannot be determined in general. Thus, a vertically incident P-wave will have an incidence angle close to either $0^{\circ}$ or $180^{\circ}$ and its azimuth will be poorly defined. A vertically incident S-wave will have a well-defined azimuth and an incidence angle close to $90^{\circ}$. Other attributes of threecomponent motion, such as rectilinearity, ellipticity, and planarity, can be derived from polarization analysis

Although Eq. (2) is straightforward, we determine incidence angle in one of two other ways, depending on which horizontal component of the real part of the dominant eigenvector is larger. If the east component is larger we use the expression

$\phi=\tan ^{-1}\left(\frac{v_{\mathrm{E}}}{v_{\mathrm{Z}}} \sqrt{1+\left(\frac{v_{\mathrm{N}}}{v_{\mathrm{E}}}\right)^{2}}\right)$

and if the north component is larger, we use

$\phi=\tan ^{-1}\left(\frac{v_{\mathrm{N}}}{v_{\mathrm{Z}}} \sqrt{1+\left(\frac{v_{\mathrm{E}}}{v_{\mathrm{N}}}\right)^{2}}\right)$.

Equations (3) and (4) are equivalent to Eq. (2), but are advantageous because they maintain the relative sign between the vertical and largest horizontal component. Using these expressions, the incidence angle can be resolved over $180^{\circ}$, which cannot be done from Eq. (2).

Following the determination of incidence angle, we find the azimuth (Fig. 3) and again consider the phase that maximizes the real part of the dominant eigenvector. However, to compute the azimuth, instead of finding the phase that maximizes the entire real part (i.e., sum of horizontal and vertical components), we find the phase that maximizes the real part of the total horizontal component only. Adjustment of the original eigenvector by this phase is well-suited for finding the azimuth, because only horizontal components are used for the azimuth determination. Once the original dominant eigenvector has been adjusted by this new phase, we find the azimuth using

$\theta=\tan ^{-1}\left(\frac{v_{\mathrm{N}}}{v_{\mathrm{E}}}\right)$

where just as for the case of the incidence angle, the azimuth can be resolved over $180^{\circ}$. Note that, in general, there is a $180^{\circ}$ ambiguity for azimuth. If the particle motion were elliptical, and the sense of motion (retrograde or prograde) were known, then the $180^{\circ}$ ambiguity could be resolved. McKee et al. (2018) recently utilized this for the analysis of ground-coupled airwaves on nearly co-located seismic and acoustic sensors. Particle motion is not always elliptical and thus the $180^{\circ}$ ambiguity exists in general.

In addition to the incidence angle and azimuth, timefrequency polarization analysis can also be used to obtain estimates of other attributes used in time-domain polarization analysis, including rectilinearity, planarity, and ellipticity (Vidale 1986). Here, the only one of these attributes we present is rectilinearity $R$, which is computed as

$R=1-\frac{\lambda_{1}+\lambda_{2}}{\lambda_{3}}$

where $\lambda_{1}, \lambda_{2}$, and $\lambda_{3}$ are the eigenvalues of the cross-spectral matrix at a single point in the time-frequency plane sorted from smallest to largest. Rectilinearity measures the degree to which the particle motion lies along a straight line and varies between 0 and 1 . As an example, a pure P-wave propagating in a homogeneous medium would have a rectilinearity of 1 along its ray path.

In this study, we use time-frequency polarization analysis to diagnose the wave type of regional Bogoslof eruption tremor. Such information on the wave type is key for properly determining reduced displacement (Aki and Koyanagi 1981), which is a measure of tremor intensity and has been computed for eruptions worldwide (McNutt and Nishimura 2008). We determine reduced displacement $\left(D_{\mathrm{R}}\right)$ of tremor by first instrumentcorrecting the recorded waveforms over the frequency band of interest containing the highest signal-to-noise ratio, from 1.5 to $10 \mathrm{~Hz}$. Further calculation of $D_{\mathrm{R}}$ at that point requires knowledge of the seismic wave type comprising the tremor. For the case of body waves (Aki and Koyanagi 1981), either P or S, $D_{\mathrm{R}}$ is simply the root-mean-square (RMS) of the vertical seismic wave displacement $U_{\mathrm{Z}}$ over a time window multiplied by the distance $D$ to the source $\left(D_{\mathrm{R}}=\operatorname{RMS}\left(U_{\mathrm{Z}}\right) \times D\right)$. Fehler $(1983)$ has shown that, for tremor composed of surface waves, $D_{\mathrm{R}}$ is the RMS vertical displacement multiplied by both the square root of the distance to the source $D$ and the square root of the wavelength $\lambda\left(D_{\mathrm{R}}=\operatorname{RMS}\left(U_{\mathrm{Z}}\right) \times D^{1 / 2} \times \lambda^{1 / 2}\right)$. 
Since the seismic recordings of the Bogoslof eruption are at regional distances, we also account for intrinsic attenuation when estimating $D_{\mathrm{R}}$. Attenuation is not normally considered when computing $D_{\mathrm{R}}$ owing to the fact that eruptions are usually monitored by local stations $(<20 \mathrm{~km}$ range). For comparison with locally determined $D_{\mathrm{R}}$ of other eruptions, we compensate for attenuation loss up to a source-receiver distance of $10 \mathrm{~km}$, which is a typical distance for stations in a local seismic network. In other words, we adjust the $D_{\mathrm{R}}$ to a source-receiver distance of $10 \mathrm{~km}$ by multiplying $D_{\mathrm{R}}$ by a factor $\exp (\pi f(D-$ $10) / c Q$ ), where $f$ is the dominant frequency, $D$ is the sourcereceiver distance, $c$ is the propagation velocity of the tremor wavefield, and $Q$ is the attenuation factor. For example, McNutt et al. (2013) use a station $14 \mathrm{~km}$ from the volcano to compute reduced displacement for the 2009 Redoubt eruption. Haney et al. (2017) calculated $D_{\mathrm{R}}$ for the 2016 Pavlof eruption by taking the median over a local network of 5 stations located between 8 and $13 \mathrm{~km}$ from the summit. When possible, taking the median or average over a group of stations reduces the impact of individual site effects at a particular station on the value of $D_{\mathrm{R}}$, similar to how a summary earthquake magnitude is averaged over several individual channel magnitudes. In this study, we summarize $D_{\mathrm{R}}$ measurements from Bogoslof using the 3 broadband stations shown in Fig. 1.

For Bogoslof eruption tremor, we assume a nominal value of 200 for the attenuation parameter $Q$ when estimating $D_{\mathrm{R}}$. Thompson et al. (2002) mention the possibility of $Q$ compensation for reduced displacement in their study of tremor at Shishaldin Volcano and mention $Q$ values of 50 and 300 for surface and body waves, respectively. In the source amplitude method (Kumagai et al. 2015), which is similar to reduced displacement, attenuation is accounted for by default and Kumagai et al. (2015) use a value of 60 for $\mathrm{S}$-waves. Prejean and Brodsky (2011) take a $Q$ value of 200 in their study of regional tremor from the Kasatochi and Augustine eruptions. We adopt a P-wave $Q$ of 200 as a general value for correcting the Bogoslof recordings to a local distance following Ohlendorf et al. (2014), who performed P-wave attenuation tomography at Okmok volcano and used a $Q$ value equal to 200 as the initial model for their inversion. We anticipate that errors in our preferred value of P-wave $Q$ equal to 200 could realistically be \pm 100 , with a range from 100 to 300 . As we discuss later, given this range, the $D_{\mathrm{R}}$ values we find could either be $20 \%$ too high or $50 \%$ too low. For example, due to this uncertainty, a $D_{\mathrm{R}}$ value of $40 \mathrm{~cm}^{2}$ estimated from the data could actually fall between 30 and $70 \mathrm{~cm}^{2}$, although this bias will be systematic over all eruptions.

\section{Results}

Ideally, determining the wave type of volcanic tremor would involve the analysis of small aperture seismic arrays (Chouet et al. 1997; Wegler and Seidl 1997; Nakamichi et al. 2013; Almendros et al. 2014); however, this is not possible in the 1.5-10 Hz band for Bogoslof where the permanent network stations are sparse and widely spaced on Umnak and Unalaska Islands. Over all the explosive events, the highest signal-to-noise ratio of the tremor fell consistently in the band from 1.5 to $10 \mathrm{~Hz}$. This means the tremor had a spectral content similar to the 2-7 $\mathrm{Hz}$ band used by Wech et al. (2018) to analyze earthquakes at Bogoslof. To gain insight into the composition of the eruption tremor wavefield, we use time-frequency polarization analysis on the regional three-component stations MAPS, OKFG, and UNV (Fig. 1). We note that seismo-acoustic coupled waves (Matoza and Fee 2014; McKee et al. 2018) from the eruption did not generally register on these stations. Two short-period seismic stations (OKRE and OKER) located on the north and east side of Okmok volcano were however prone to significant seismo-acoustic coupling over the course of the eruption. Such coupling was clear on OKRE and OKER for impulsive eruptive events due to the delay between the arrival of seismic waves and ground-coupled airwaves.

Shown in Fig. 4 are several polarization attributes, a seismogram, and spectrogram for eruptive event 36 on February 20, 2017 as recorded on station MAPS. The patterns observed in this figure are key to unraveling the wavefield composition of the Bogoslof eruption tremor in the band from 1.5 to $10 \mathrm{~Hz}$. The time period shown spans the end of the 5-h-long precursory earthquake swarm and the beginning of the eruption tremor. The presence of two precursory earthquakes in Fig. 4 illustrates the distinct polarization signatures of the separated earthquake phase arrivals. These signatures are the combined result of source, path, and site effects and are important since eruption tremor, as a continuous and sustained signal, does not present individually separated phases. Labeled in Fig. $4 \mathrm{~d}$ are three phase arrivals for the final precursory earthquake: the P-wave, S-wave, and T-wave. The presence of the T-wave, a converted hydroacoustic wave that primarily travels through the water column, was the result of the mostly submarine nature of the Bogoslof eruption. It was utilized by Wech et al. (2018) to classify Bogoslof earthquakes and form a conceptual model to explain the occurrence of precursory, co-eruptive, and post-eruptive earthquakes over the course of the eruption sequence.

The individually arriving earthquake phases show clear signatures in terms of incidence angle and azimuth in Fig. 4a and $b$. The P-wave arrival is marked by strong vertical incidence at around $5 \mathrm{~Hz}$, with mainly red and blue colors in the plot. S-waves, on the other hand, have mostly horizontal incidence as indicated by the green colors in Fig. 4a. The S-wave arrival is also characterized by an azimuth of nearly $0^{\circ}$ over a wide frequency band in Fig. 4b, the result of this arrival being mainly polarized on the north component. Note the azimuth for the P-waves, especially the portions with strong vertical incidence, is poorly defined on account of the particle motion 
being mostly vertical. The T-wave has more vertical motion than the S-waves, as evidenced by the greater amount of blue and red at the time of its arrival in Fig. 4a; however, it does not have similarly strong vertical polarization near $5 \mathrm{~Hz}$ as observed for the $\mathrm{P}$-waves. We also note that $\mathrm{P}$ - and $\mathrm{S}$-waves from the earthquakes show strong rectilinearity in Fig. 4c, with significant rectilinearity extending from 5 to $10 \mathrm{~Hz}$ for Pwaves and $2-8 \mathrm{~Hz}$ for $\mathrm{S}$-waves.

We keep these polarization signatures of the earthquake phases in mind while analyzing the signature of the eruption tremor occurring over the latter half of Fig. 4. In Fig. 4a, we clearly observe that the pattern of incidence angle for eruption tremor is similar to the distribution seen for P-waves of the precursory earthquakes.
Most striking is the strong vertical polarization at around $5 \mathrm{~Hz}$. This is clear evidence that the regional wavefield of eruption tremor from Bogoslof is dominated by Pwaves generated at the source in the band from 1.5 to $10 \mathrm{~Hz}$, as would be expected for a wavefield arising from a fluctuating, pressure-driven process (Aki and Koyanagi 1981), as opposed to shear failure. We also note the lack of strong rectilinearity for the eruption tremor, compared with the P-waves from the precursory quakes. This can be partially explained by the overall lack of rectilinearity for P-waves below $5 \mathrm{~Hz}$, where most of the tremor energy exists and possibly also path effects such as multipathing combined with the protracted source-time function.
Fig. 4 Transition from precursory earthquake swarm to eruption tremor during event 36 on February 20, 2017. Horizontal scale in all panels is time in UTC. a-c Time-frequency polarization attributes, $\mathbf{d}$ the vertical component seismogram for station MAPS, and $\mathbf{e}$ its spectrogram. Phase arrivals are labeled for the final earthquake in the swarm in $\mathbf{d}$ and the previous earthquake is plotted prior to it. Eruption tremor is also labeled in $\mathbf{d}$. $\mathbf{a}, \mathbf{b}, \mathbf{c}$, and $\mathbf{e}$ Boxes show the time windows of the earthquake phase arrivals and eruption tremor. In a, the eruption tremor beginning after 2:08 UTC is observed to have an incidence angle signature most similar to the P-waves, suggesting that the eruption tremor at the regional distance of station MAPS is primarily composed of P-waves
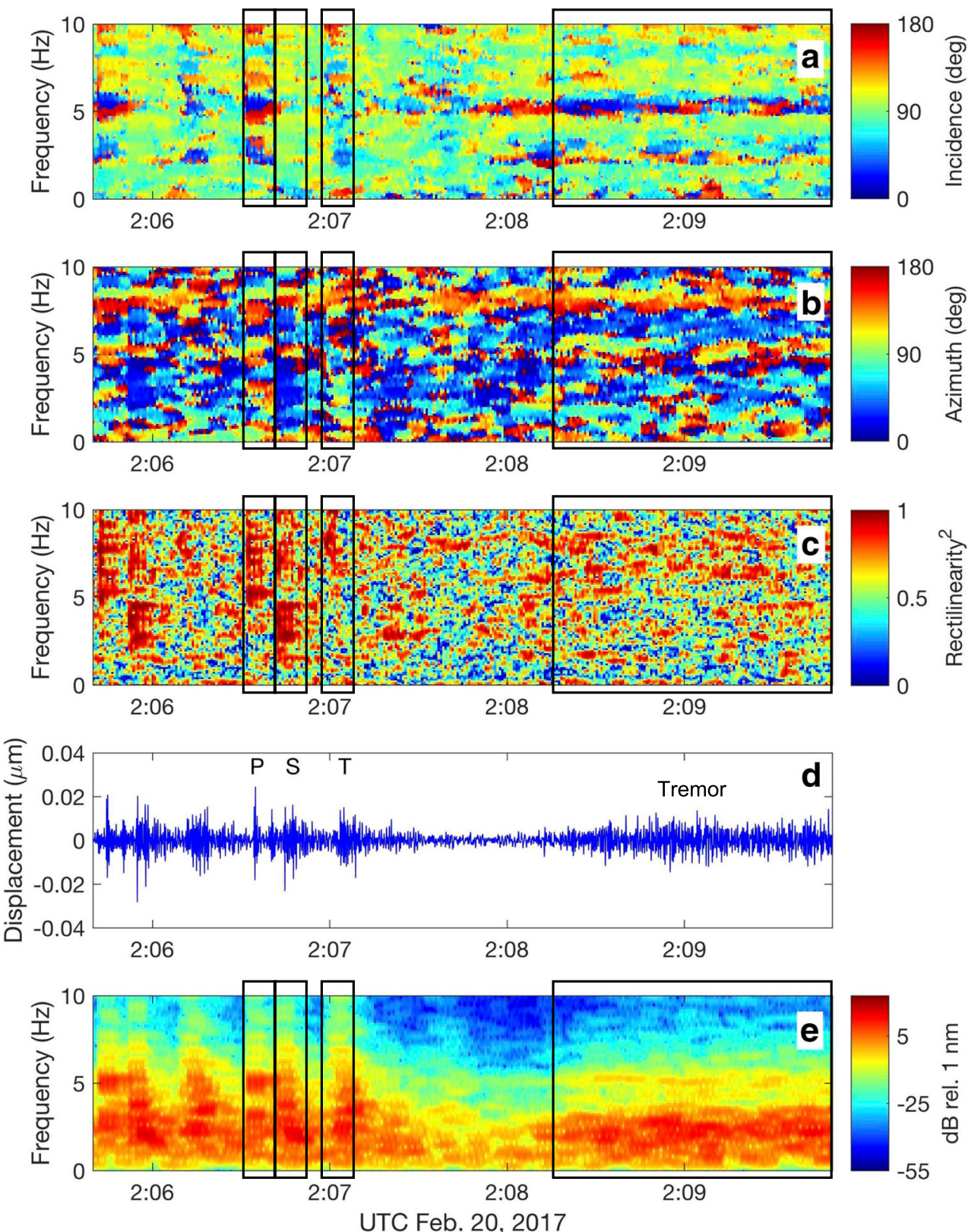

UTC Feb. 20, 2017 
The dominance of $\mathrm{P}$-waves over T-waves for the eruption tremor can be further understood from Fig. $2 b$ of Wech et al. (2018), which shows that the ability of a buried source within the Bogoslof edifice to generate T-waves is maximized at a depth of approximately $1 \mathrm{~km}$. Above and below this depth, a buried source generates progressively weaker T-waves, especially as it approaches the surface and for depths below $4 \mathrm{~km}$ (Wech et al. 2018). Eruption tremor, which is presumably sourced at shallow depths immediately beneath the vent, is therefore a relatively poor producer of T-wave energy at Bogoslof. This provides further explanation for the dominance of regional $\mathrm{P}$-waves in the eruption tremor wavefield between 1.5 and $10 \mathrm{~Hz}$. Although we have highlighted the polarization patterns of eruption tremor in Fig. 4 for event 36 , we have analyzed other eruptive events and the polarization signatures of event 36 eruption tremor are typical of all Bogoslof eruption tremor. Supplemental Figures 1-5 show that similar polarization signatures exist for other instances of eruption tremor that occurred between January and July 2017. We selected these 5 examples of tremor since coeruptive earthquakes did not significantly interfere with the tremor signals and later we discuss how we handled this situation for the estimation of $D_{\mathrm{R}}$.

Based on the evidence for an eruption tremor wavefield dominated by P-waves in the band from 1.5 to $10 \mathrm{~Hz}$, we proceed to estimate reduced displacement $\left(D_{\mathrm{R}}\right)$ for several Bogoslof eruptive periods discussed in Wech et al. (2018). These eruptive periods correspond to times of infrasound detections on the Okmok microphone array, such that it can be safely concluded that Bogoslof was in fact erupting during these time periods. By considering these times, we are assured to only analyze co-eruptive rather than non-eruptive tremor and moreover we know the eruption timing with high precision. There are 59 time periods considered by Wech et al. (2018), but several of the time periods are individual pulses within a single explosive event. Thus, the 59 time periods actually only cover 27 of the 70 total explosive events. However, some of the most significant events, at least in terms of plume height and duration, are included in the time periods from Wech et al. (2018), including the eruptions that took place on December 22 (event 7), January 9 (event 17), January 31 (event 29), February 20 (event 36), March 8 (event 37), May 17 (event 39), May 28 (event 40), June 10 (event 48), and August 7 (event 63). The numbering of eruptive events is discussed further in Coombs et al. (2018) and Coombs et al. (2019). One of the eruptive time periods considered by Wech et al. (2018), on December 12, 2016, did not produce detectable seismicity on the regional stations (only infrasound) and we thus do not include it in our analysis. Furthermore, the final eruptive time period considered by Wech et al. (2018), on August 28, 2017, had a duration of only $4 \mathrm{~s}$, which is too short to be considered sustained eruption tremor. Thus, we consider 25 of the original 27 events as derived from the eruptive periods in Wech et al.
(2018). The eruptive periods are defined in terms of arrival time at the Okmok microphone array and therefore we subtract the nominal acoustic travel time $(180 \mathrm{~s})$ to obtain eruption origin times at the volcano.

An added complication for $D_{\mathrm{R}}$ estimation is that coeruptive earthquakes often occurred at Bogoslof, including earthquakes greater than M2.0. The enriched catalog produced by Wech et al. (2018) contains these earthquakes, and we avoid the times of the earthquake signals when computing $D_{\mathrm{R}}$. We do so assuming the discrete earthquakes likely do not reflect the same process as sustained eruption tremor. With this in mind, we compute $D_{\mathrm{R}}$ over 1-min-long time windows during eruptive periods in which earthquakes did not occur. For station MAPS, this means we delay the origin time of co-eruptive earthquakes given by Wech et al. (2018) by $15 \mathrm{~s}$, which is the travel time over $73 \mathrm{~km}$ at the approximate P-wave speed of $5 \mathrm{~km} / \mathrm{s}$. From that onset time, we avoid the next $50 \mathrm{~s}$ of data since it includes the $\mathrm{P}$-wave, $\mathrm{S}$-wave, and $\mathrm{T}$ wave earthquake arrivals. To compute a summary $D_{\mathrm{R}}$ for an event, we compensate for attenuation losses as discussed previously by using a $Q$ value of 200 . For the attenuation compensation, we use a dominant tremor frequency of $3 \mathrm{~Hz}$ and a wave speed of $5 \mathrm{~km} / \mathrm{s}$, which is typical for P-waves in the upper crust. For each eruptive period, we then average the 1min-long $D_{\mathrm{R}}$ values to obtain a single value for the eruptive time period. If an explosive event has several pulses of activity, we take the maximum of the average $D_{\mathrm{R}}$ values for the individual pulses as the $D_{\mathrm{R}}$ value for that event. Searcy and Power (2020) discuss and classify the number of pulses within explosive events at Bogoslof.

We plot the result of this approach for $D_{\mathrm{R}}$ estimation in Fig. 5, which shows $D_{\mathrm{R}}$ values for each of the 25 Bogoslof events considered at station MAPS (Fig. 5a) and OKFG (Fig. $5 b)$. The $D_{\mathrm{R}}$ estimates for MAPS and OKFG are overall consistent, as are the relative variations between the two stations. Note that OKFG was inoperable during event 16, which is why no $D_{\mathrm{R}}$ value is plotted for that event in Fig. 5b. Although we do not plot $D_{\mathrm{R}}$ for station UNV in Fig. 5, it was quite close to the $D_{\mathrm{R}}$ values obtained for stations MAPS and OKFG. This provides additional evidence against possible dominance of $\mathrm{T}$ waves in eruption tremor, since T-waves from earthquakes, such as those seen in Fig. 4 for station MAPS, were not strongly observed at station UNV. The lack of earthquake T-waves at UNV can be understood from the fact that UNV sits farther back from the Unalaska coast that is closest to Bogoslof than station MAPS, so that T-waves coupling into the solid Earth near the coast may have dissipated by the time they reached UNV. In spite of the decreased T-wave energy at UNV, the $D_{\mathrm{R}}$ values are in line with estimates from OKFG and MAPS.

Note that we plot $D_{\mathrm{R}}$ values for each explosive event in Fig. 5, one in black and the other in red. The estimate in black is the result of naively computing $D_{\mathrm{R}}$ without removing the times of earthquakes from the enriched catalog of Wech et al. 
Fig. 5 Average reduced displacement computed on stations MAPS (a) and OKFG (b) for the eruptive periods discussed in Wech et al. (2018), which comprises a subset of all Bogoslof events. Event number corresponding to the eruptive period is shown along the bottom. Black bars are the result of simply computing reduced displacement assuming a tremor wavefield composed of $\mathrm{P}$-waves over the eruptive time interval indicated by the Okmok infrasound array. Red bars show the result of calculating reduced displacement while removing the effect of co-eruptive earthquakes detected by Wech et al. (2018). Events for which there is a large discrepancy between the black and red bars had more and stronger co-eruptive earthquakes than those showing little difference
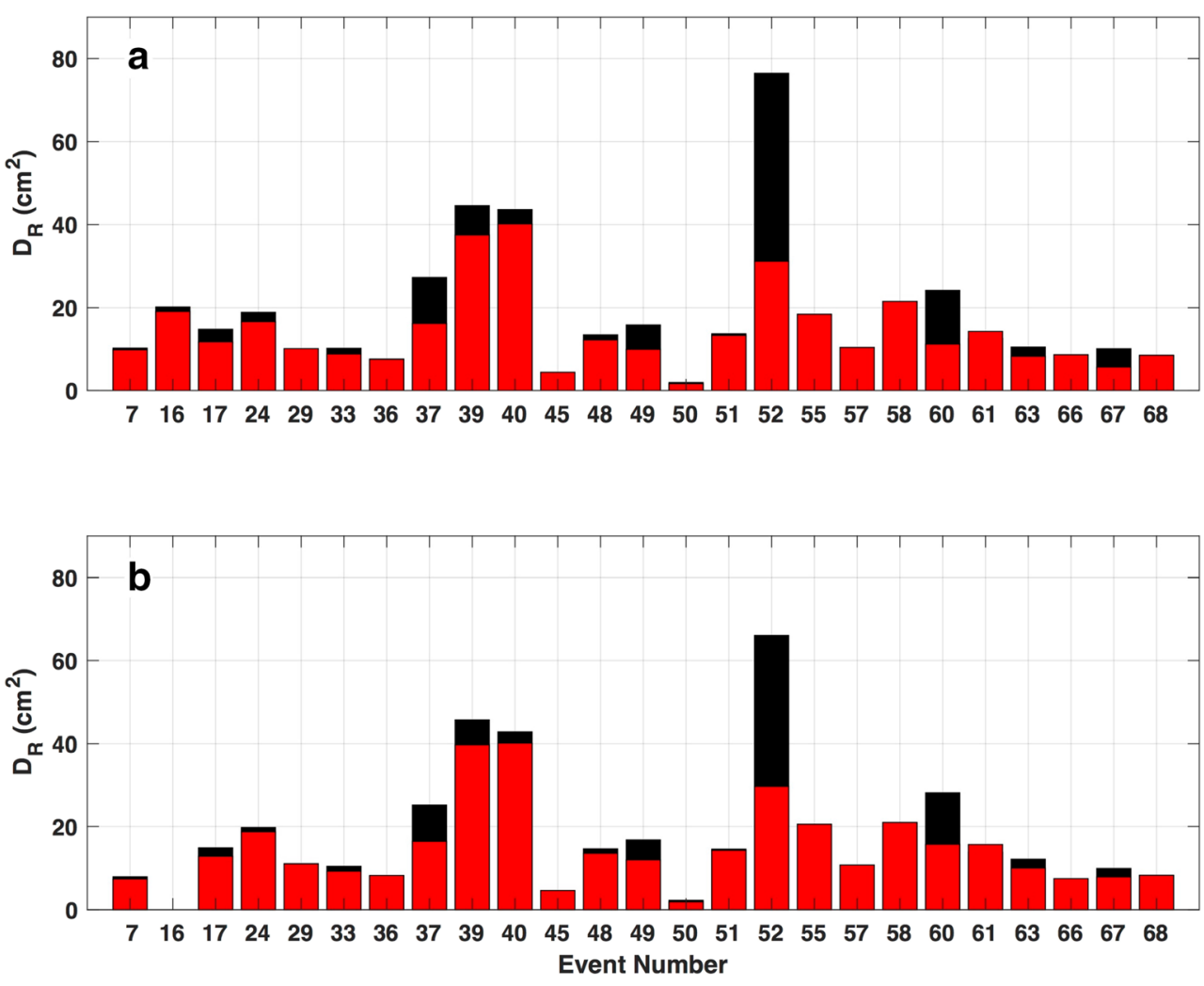

(2018). The red estimate removes the times of earthquakes and, as expected, is observed to be less than or equal to the black estimate. Events with larger differences between the red and black estimates of $D_{\mathrm{R}}$ have stronger and more frequent coeruptive earthquakes. Peak $D_{\mathrm{R}}$ values for eruption tremor are observed to have occurred during events 39 and 40, with values of approximately $40 \mathrm{~cm}^{2}$; in fact, the tremor from event 40 is plotted in Fig. 2a.

We cross plot the average reduced displacement versus maximum plume height (Schneider et al. 2020) in Fig. 6 for the first 10 events shown in Fig. 5, spanning the time period between December 22, 2016, and May 28, 2017. A weak correlation is observed to exist between average $D_{\mathrm{R}}$ and plume height on a log-log plot for these events. A power-law fit of the form $D_{\mathrm{R}} \sim H^{\mathrm{b}}$, where $H$ indicates plume height, yields an exponent for the fit of 1.4 - close to the exponent of $1.8 \mathrm{ob}-$ tained by McNutt (1994) when considering several worldwide eruptions. Haney et al. (2017) also found an exponent for the power-law fit of 1.7 during the waxing phase (Fee et al. 2017) of the 2016 eruption of Pavlof. However, the correlation observed in Fig. 6 breaks down for the later events shown in Fig. 5 after May 28. In particular, event 63 on August 7, 2017 produced a high-altitude volcanic plume in excess of 10.8 km ASL (Schneider et al. 2020), but had relatively weak eruptive tremor with a $D_{\mathrm{R}}$ on the order of $10 \mathrm{~cm}^{2}$. Such an effect could be explained by the evolution of the vent geometry over the course of the eruption (Fee et al. 2017), changes in atmospheric conditions (Tupper et al. 2009), or other factors.
McNutt et al. (2010) discuss low $D_{\mathrm{R}}$ eruptions from Augustine Volcano that generated high ash plumes and suggested the eruptions resulted from batches of magma with relatively uniform distribution of volcanic gases. Another notable exception to the trend in Fig. 6 was event 18 on January

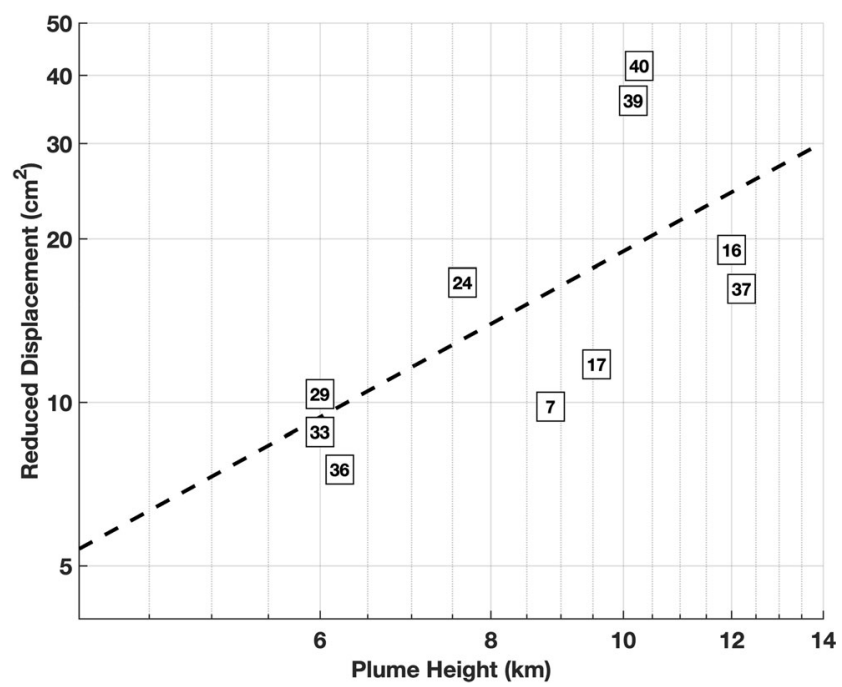

Fig. 6 Average reduced displacement versus plume height for the first 10 events listed in Fig. 5, which occurred during the first 5 months of the eruption. The marker for the data points is the event number in a small box. We plot a power-law fit of the data as a dashed black line and a weak correlation $\left(R^{2}=0.43\right)$ is observed. The exponent of the power law is 1.4 , close to values previously determined by McNutt (1994) and Haney et al. (2017). Events following the first 10 listed in Fig. 5 deviated from this trend 
12, 2017. That eruption had strong tremor but generated an ash plume that did not rise above 4-km ASL (Schneider et al. 2020). Event 18 is not shown in Figs. 5 and 6 since it was not included in the eruptive catalog based on OKIF infrasound detections used by Wech et al. (2018). Ash plume height from Bogoslof does not appear to correlate well with infrasound parameters either (Fee et al. 2020).

In Fig. 7, we return to time-frequency polarization attributes but now for another type of tremor besides eruption tremor from Bogoslof. We do so in order to demonstrate the differences in these signals and the ability to discriminate between them based on their polarization in the time-frequency domain. Tectonic, or non-volcanic, tremor commonly occurs in the Aleutian Islands near Unalaska Island ( $\mathrm{Li}$ and Ghosh 2017) and is the result of shear slip at the plate interface (Wech and Creager 2007). The source region of tectonic tremor is trenchward of the volcanic arc (opposite to the back arc direction of Bogoslof), at depths of $\sim 30 \mathrm{~km}$ along the plate interface. Coombs et al. (2018) have pointed out that tectonic tremor added to the complexity of seismic monitoring of the Bogoslof eruption and that at times it was mistaken for co- eruptive tremor. The confusion is understandable given that tectonic tremor appears in the same $1.5-10 \mathrm{~Hz}$ frequency band as Bogoslof co-eruptive tremor. We focus on an episode of tectonic tremor in Fig. 7 that immediately preceded a short burst of Bogoslof tremor which followed event 55 on June 30, 2017. Although this burst of Bogoslof tremor did not occur during event 55 , it had similar polarization properties as typical co-eruptive tremor. It is accounted for in the catalog of elevated seismicity presented in Searcy and Power (2020). In particular, the incidence angle signature in Fig. 7a starting at 6:16 UTC is the same as observed in Fig. 4a. For several minutes prior to this tremor burst, lower amplitude tectonic tremor was occurring from 6:00 to 6:15 UTC as seen Fig. $7 \mathrm{~b}$ and $\mathrm{c}$. Even though it has similar frequency content and is only slightly lower in amplitude than the co-eruptive tremor burst, the incidence angle signature of the tectonic tremor appears quite different in Fig. 7a. Overall, the incidence angles are closer to $90^{\circ}$ (i.e., not so much red and blue colors), indicating motion closer to horizontal. This agrees with what is expected for tectonic tremor since it is dominated by horizontally polarized S-waves generated mostly below the
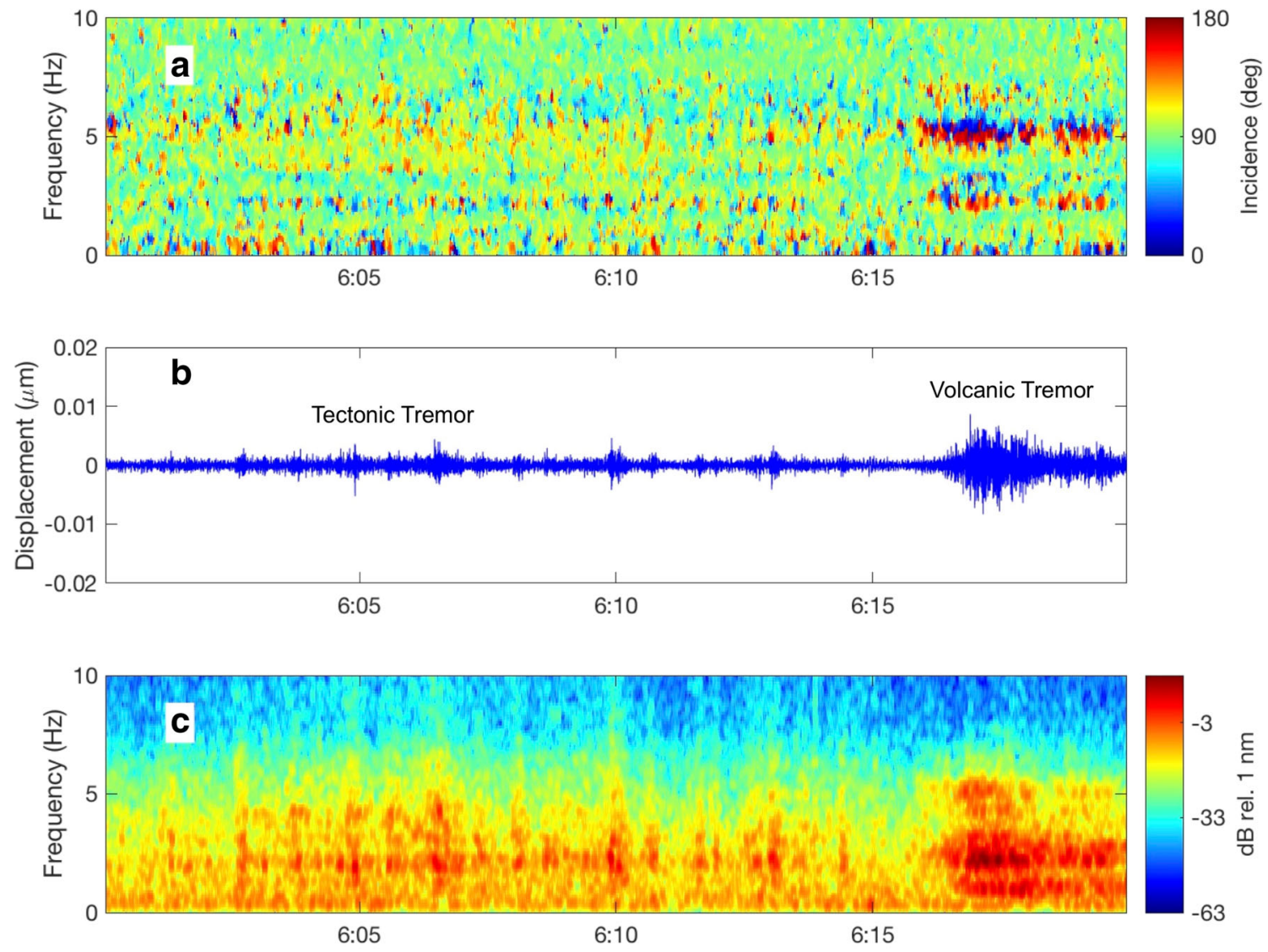

UTC June 30, 2017

Fig. 7 Coincident occurrence of tectonic and volcanic tremor on June 30, 2017, as recorded on station MAPS. Tectonic tremor between 6:00 and 6:15 UTC is weaker and precedes the volcanic tremor, as shown in $\mathbf{b}$. Both types of tremor are observed to share similar spectral content (c); however, their polarization attributes in a are different owing to their different source processes. Thus, the incidence angle signature is a clear discriminant between the two types of tremor for the Bogoslof eruption 
station at the plate interface (Wech and Creager 2007). The incidence angle signature clearly discriminates tectonic tremor from co-eruptive tremor and shows that time-frequency polarization attributes reflect both source and site effects.

In addition to the eruption tremor observations we have presented in the main frequency band from 1.5 to $10 \mathrm{~Hz}$, where the tremor has the highest signal-to-noise ratio, we have also looked for regional tremor in lower, noisier frequency bands. Eruption tremor was limited to the main frequency band for most of the 70 eruptive events; however, the eruption with the highest average $D_{\mathrm{R}}$ value in Fig. 5, event 40, produced measurable eruption tremor in the very-long-period (VLP) band from 0.05 to $0.15 \mathrm{~Hz}$ as shown in Fig. 8c. Although not shown in Fig. 8, event 39, which had the second strongest eruption tremor in Fig. 5, also produced significant VLP tremor. These observations are noteworthy since the VLP tremor registers as far as at least $100 \mathrm{~km}$ range, at station UNV. This low-frequency tremor is difficult to observe since noise is much higher between 0.05 and $0.15 \mathrm{~Hz}$ than the 1.5 $10 \mathrm{~Hz}$ band, owing to the presence of the oceanic microseism. Thus, VLP tremor was likely occurring at some level for the other events, but only registered above the noise for events 39 and 40 due to their high amplitude tremor. Such lowfrequency eruption tremor has been observed previously during the 2008 eruption at Okmok Volcano (Haney 2010). In contrast to tremor in the $1.5-10 \mathrm{~Hz}$ band, the VLP tremor is primarily composed of Rayleigh waves. We have confirmed this by performing beamforming (Fig. $8 \mathrm{a}$ and $\mathrm{b}$ ) using the vertical component of stations in the local seismic network on Unalaska Island (Fig. 1), similar to the analysis by Haney (2010). The beamforming indicates waves coming from the general direction of Bogoslof at a propagation velocity of $3.5 \mathrm{~km} / \mathrm{s}$, a speed expected for Rayleigh waves in the 0.05 $0.15 \mathrm{~Hz}$ band. Beamforming was possible for these low frequencies on a local seismic network since these VLP Rayleigh waves have a wavelength of roughly $30 \mathrm{~km}$. Thus, relative to
Fig. 8 Very-long-period (VLP) tremor during event 40 on May 28, 2017. a and b Wellresolved backazimuths and trace velocities of the seismic waves, computed from beamforming in the band $0.05-0.15 \mathrm{~Hz}$, using the vertical components of the broadband seismic network on Unalaska Island shown in Fig. 1. Trace velocities of $3.5 \mathrm{~km} / \mathrm{s}$ are consistent with Rayleigh waves at these frequencies. Note that the backazimuths deviate somewhat from the expected backazimuth (red line) to Bogoslof due to unknown complexity of the wavefield. c A seismogram from station UNV in the same low frequency band. Whereas P-waves dominate the higher frequency tremor wavefield, VLP tremor is primarily composed of Rayleigh waves. However, due to higher noise levels in the $0.05-0.15 \mathrm{~Hz}$ band, VLP tremor is only observable for events 39 and 40
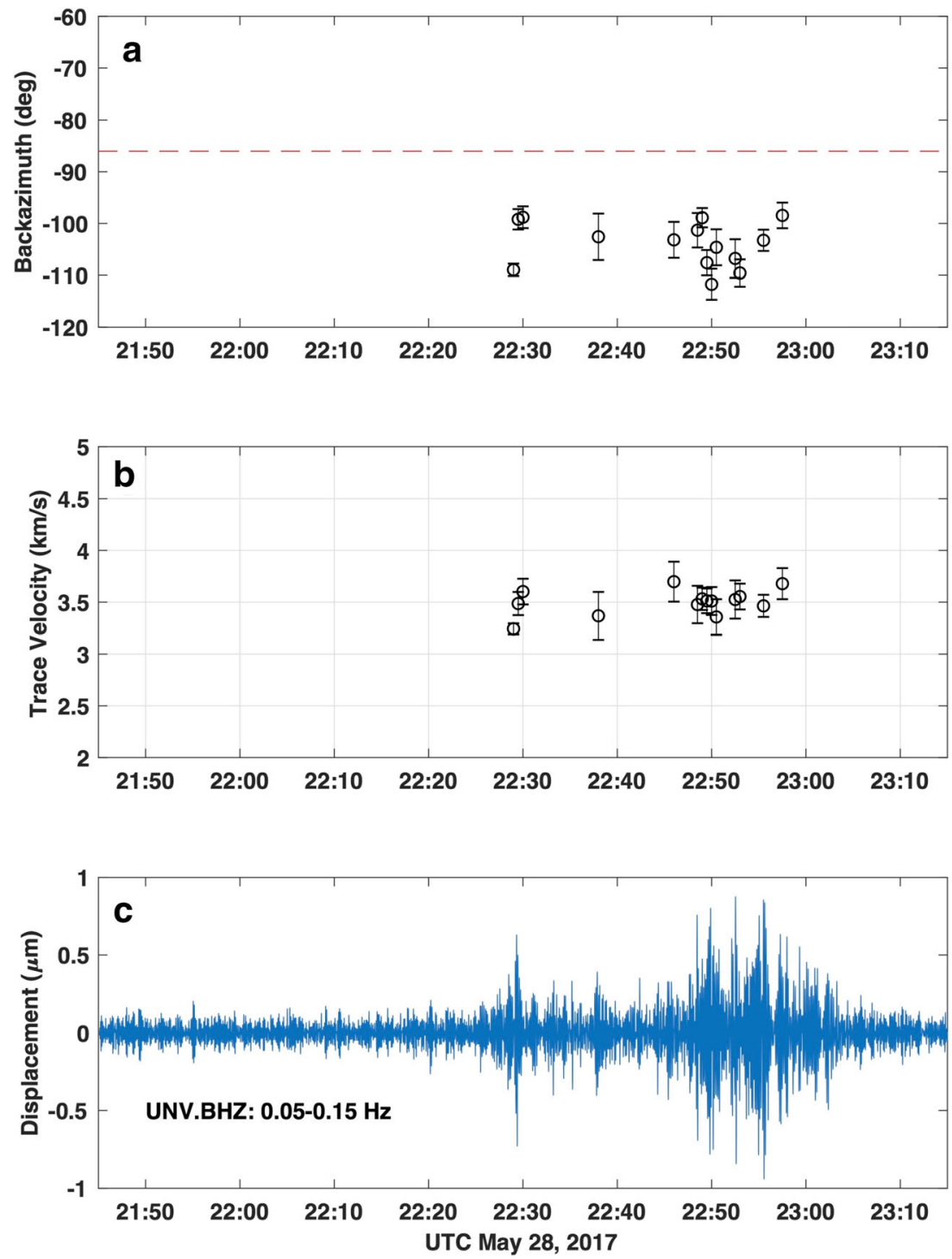
the wavelength, the "sparse" seismic network on Unalaska Island becomes relatively dense. We note that timefrequency polarization analysis proved to not be useful for determining the wave type of the VLP tremor primarily because we do not have polarization observations from isolated phases in the $0.05-0.15 \mathrm{~Hz}$ band, in contrast to the higher frequencies. This is because the earthquakes at Bogoslof are small enough that their lower corner frequency is well above the VLP band. In addition, it may be that the VLP tremor is comprised of both Love and Rayleigh waves, and thus the three-component polarization is scrambled between the two types of surface waves. However, the vertical components are unaffected by the presence of Love waves and thus can be used for beamforming as we have shown.

\section{Discussion}

Having estimated the average reduced displacement for the various Bogoslof eruptive events, we can put the values in context with measurements from other eruptions. The highest average $D_{\mathrm{R}}$ value of approximately $40 \mathrm{~cm}^{2}\left(30-70 \mathrm{~cm}^{2}\right.$ taking into account $Q$ uncertainty) observed during events 39 and 40 is less than the maximum value of $78 \mathrm{~cm}^{2}$ reported for the 2009 Redoubt eruption by McNutt et al. (2013). However, as discussed, the $D_{\mathrm{R}}$ values we report are event-averaged and the maximum $D_{\mathrm{R}}$ values were usually on the order of twice as high as the averaged ones. We have chosen to present average $D_{\mathrm{R}}$ values since our intention is to measure sustained eruption tremor that is representative of the entire event and not from a short time period corresponding to the maximum within an event. Thus, the tremor levels from Bogoslof and Redoubt in 2009 are comparable. Haney et al. (2017) obtain a peak value of approximately $17 \mathrm{~cm}^{2}$ for the 2016 Pavlof eruption, with an average value of roughly $10 \mathrm{~cm}^{2}$. Note that both of these estimates, which utilized local stations, assumed the eruption tremor wavefield was dominated by surface waves. Furthermore, the $D_{\mathrm{R}}$ estimates for Redoubt and Pavlof do not account for the possibility of co-eruptive earthquakes, as we have done for Bogoslof. This is not an issue for Pavlof, since earthquake seismicity there is rare, but would be worth re-examining for the Redoubt 2009 eruption.

We applied time-frequency polarization analysis since reduced displacement estimates require information on the wave type; this analysis showed that regional eruption tremor was dominated by $\mathrm{P}$-wave generation at the source in the band from 1.5 to $10 \mathrm{~Hz}$. The dominance of $\mathrm{P}$-waves in tremor points to a fluctuating, pressure-driven source rather than a shear source process, such as shearing against the conduit walls. The situation is also in contrast to the numerous documented instances of eruption tremor at local distances being composed of surface waves. Future work will investigate other examples of regionally recorded eruption tremor (Fig. 2) to diagnose the wavefield composition. Although the time-frequency polarization method is well-suited for tremor analysis, we can envision future improvements to it, such as the use of wavelets (D'Auria et al. 2010; Jones et al. 2016) instead of the conventional short time-window Fourier transform used here.

Although tremor in the $1.5-10 \mathrm{~Hz}$ band is primarily $\mathrm{P}$ waves, we also observe VLP tremor composed of Rayleigh waves in the $0.05-0.15 \mathrm{~Hz}$ band for the strongest events. These low-frequency waves give an interesting and complementary view of the eruption tremor, and many past eruptions have not have been characterized in this band due to the lack of broadband seismometers (McNutt and Nishimura 2008). By comparing Figs. $2 \mathrm{a}$ and $8 \mathrm{c}$, it is evident that the displacement of the VLP tremor exceeds that of the typical tremor in the band from 1.5 to $10 \mathrm{~Hz}$, even though the typical tremor has a much higher signal-to-noise ratio. In fact, we can estimate $D_{\mathrm{R}}$ independently for the VLP tremor using the surface-wave formulation of Fehler (1983). We find an average value of approximately $100 \mathrm{~cm}^{2}$ over the course of event 40 , roughly twice as high as the estimate of $40 \mathrm{~cm}^{2}$ from P-waves in the $1.5-10 \mathrm{~Hz}$ band. Note that due to the low frequency band and the resulting weak attenuation expected for these VLP Rayleigh waves, we do not compensate for attenuation in the $D_{\mathrm{R}}$ estimate from VLP tremor since it would not change the value significantly. Future work will investigate the partitioning of eruption energy between the two types of waves. Although unequal, these two $D_{\mathrm{R}}$ estimates are reasonably close and represent different ways of quantifying the size of eruption tremor, in a similar way as a large tectonic earthquake can have both a body-wave and a surface-wave magnitude.

\section{Conclusions}

We have analyzed eruption tremor from Bogoslof during the 2016-2017 eruption through the combined use of a method of time-frequency polarization analysis and reduced displacement. We find that the regional eruption tremor wavefield is dominated by P-waves between 1.5 and $10 \mathrm{~Hz}$. This indicates that the tremor originated from a fluctuating pressure-driven source. With knowledge of the primary wave type, we estimate average reduced displacement for several events of the Bogoslof eruption and observe peak values on three broadband seismometers of up to $40 \mathrm{~cm}^{2}\left(30-70 \mathrm{~cm}^{2}\right.$ taking into account realistic uncertainties in $Q$ ). Care has been taken in the process of estimating the reduced displacement of sustained eruption tremor to avoid time windows containing co-eruptive earthquakes. We document a weak correlation over the first 5 months of the eruption between higher amplitude sustained tremor and higher altitude plumes. There are notable exceptions to the trend which deserve further investigation in order to shed light on the relationship between the eruptive tremor at Bogoslof and the generation of ash plumes. Although P- 
waves comprised most of the eruption tremor, very-longperiod tremor observed during two of the most seismically energetic events is dominated by Rayleigh waves. This can be explained by a transition in the regional tremor wavefield from primarily Rayleigh waves to primarily $\mathrm{P}$-waves at a frequency between 0.15 and $1.5 \mathrm{~Hz}$. In summary, we have demonstrated time-frequency domain methods for diagnosing wavefield composition and character which should be generally applicable to assessing the wave type of tremor during volcanic eruptions.

Acknowledgments We thank Jean Soubestre, Steve McNutt, Roger Denlinger, and an anonymous reviewer for their comments on this paper. Data used in this study are available at the IRIS-DMC. RSM was supported by NSF grants EAR-1614855 and EAR-1847736. Any use of trade, firm, or product names is for descriptive purposes only and does not imply endorsement by the U.S. Government.

\section{References}

Aki K, Koyanagi RY (1981) Deep volcanic tremor and magma ascent mechanism under Kilauea, Hawaii. J Geophys Res Solid Earth 86: 7095-7109

Almendros J, Abella R, Mora MM, Lesage P (2014) Array analysis of the seismic wavefield of long-period events and volcanic tremor at Arenal volcano, Costa Rica. J Geophys Res Solid Earth 119:55365559

Chouet BA, Matoza RS (2013) A multi-decadal view of seismic methods for detecting precursors of magma movement and eruption. $\mathrm{J}$ Volcanol Geotherm Res 252:108-175

Chouet B, Saccorotti G, Martini M, Dawson P, De Luca G, Milana G, Scarpa R (1997) Source and path effects in the wave fields of tremor and explosions at Stromboli Volcano, Italy. J Geophys Res 102(B7): $15,129-15,150$

Coombs ML, Wech AG, Haney MM, Lyons JJ, Schneider DJ, Schwaiger HF, Wallace KL, Fee D, Freymueller JT, Schaefer JR, Tepp G (2018) Short-term forecasting and detection of explosions during the 2016-2017 eruption of Bogoslof volcano, Alaska. Front Earth Sci 6:122. https://doi.org/10.3389/feart.2018.00122

Coombs M, Wallace K, Cameron C, Lyons J, Wech A, Angeli K, Cervelli P (2019) Overview, chronology, and impacts of the 2016-2017 eruption of Bogoslof volcano. Bull Volcanol 81:62. https://doi.org/ 10.1007/s00445-019-1322-9

D'Auria L, Giudicepietro F, Martini M, Orazi M, Peluso R, Scarpato G (2010) Polarization analysis in the discrete wavelet domain: an application to volcano seismology. Bull Seismol Soc Am 100(2):670683

Denlinger RP, Moran SC (2014) Volcanic tremor masks its seismogenic source: results from a study of noneruptive tremor recorded at Mount St. Helens, Washington. J Geophys Res Solid Earth 119: 2230-2251

Diallo M, Kulesh M, Holschneider M, Scherbaum F (2005) Instantaneous polarization attributes in the time-frequency domain and wavefield separation. Geophys Prospect 53:723-731

Endo ET, Murray T (1991) Real-time seismic amplitude measurement (RSAM): a volcano monitoring and prediction tool. Bull Volcanol 53:533-545
Ereditato D, Luongo G (1994) Volcanic tremor wave field during quiescent and eruptive activity at Mt. Etna (Sicily). J Volcanol Geotherm Res 61:239-251

Fee D, Haney MM, Matoza RS, Van Eaton AR, Cervelli P, Schneider DJ, Iezzi AM (2017) Volcanic tremor and plume height hysteresis from Pavlof Volcano, Alaska. Science 355(6320):45-48

Fee D, Lyons J, Haney M, Wech A, Waythomas C, Diefenbach AK, Lopez T, Van Eaton A, Schneider D (2020) Seismo-acoustic evidence for vent drying during shallow submarine eruptions at Bogoslof volcano, Alaska. Bull Volcanol 82:2. https://doi.org/10. 1007/s00445-019-1326-5

Fehler M (1983) Observations of volcanic tremor at mount St Helens volcano. J Geophys Res 88:3476-3484

Haney MM (2010) Location and mechanism of very long period tremor during the 2008 eruption of Okmok Volcano from interstation arrival times. J Geophys Res 115:B00B05

Haney MM, Matoza RS, Fee D, Aldridge DF (2017) Seismic equivalents of volcanic jet scaling laws and multipoles in acoustics. Geophys J Int 213(1):623-636

Jones JP, Eaton DW, Caffagni E (2016) Quantifying the similarity of seismic polarizations. Geophys J Int 204:968-984

Konstantinou KI, Schlindwein V (2002) Nature, wavefield properties and source mechanism of volcanic tremor: a review. J Volcanol Geotherm Res 119(1-4):161-187

Kumagai H, Mothes P, Ruiz M, Maeda Y (2015) An approach to source characterization of tremor signals associated with eruptions and lahars. Earth Planets Space 67:178, 12 p

Li B, Ghosh A (2017) Near-continuous tremor and low-frequency earthquake activities in the Alaska-Aleutian subduction zone revealed by a mini seismic array. Geophys Res Lett 44:5427-5435

Lyons JJ, Iezzi A, Fee D, Schwaiger HF, Wech AG, Haney MM (2020) Infrasound generated by the 2016-2017 shallow submarine eruption of Bogoslof volcano, Alaska. Bull Volcanol. https://doi.org/10. 1007/s00445-019-1355-0

Matoza RS, Fee D (2014) Infrasonic component of volcano-seismic eruption tremor. Geophys Res Lett 41:1964-1970. https://doi.org/10. 1002/2014GL059301

Matoza RS, Fee D, Green DN, Le Pichon A, Vergoz J, Haney MM, Mikesell TD, Franco L, Valderrama OA, Kelley MR, McKee K, Ceranna L (2018) Local, regional, and remote seismo-acoustic observations of the April 2015 VEI 4 eruption of Calbuco volcano, Chile. J Geophys Res Solid Earth 123:3814-3827

McKee K, Fee D, Haney M, Matoza RS, Lyons J (2018) Infrasound signal detection and back azimuth estimation using groundcoupled airwaves on a seismo-acoustic sensor pair. J Geophys Res Solid Earth 123:6826-6844

McNutt SR (1994) Volcanic tremor amplitude correlated with eruption explosivity and its potential use in determining ash hazards to aviation, U.S. Geol Den Surv Bull 2047:377-385

McNutt SR, Nishimura T (2008) Volcanic tremor during eruptions: temporal characteristics, scaling and constraints on conduit size and processes. J Volcanol Geotherm Res 178(1):10-18

McNutt SR, Miller TP, Taber JJ (1991) Geological and seismological evidence of increased explositivity during the 1986 eruptions of Pavlof volcano, Alaska. Bull Volcanol 53:86-98

McNutt SR, Tytgat G, Estes SA, Stihler SD (2010) A parametric study of the January 2006 explosive eruptions of Augustine Volcano, using seismic, infrasonic, and lightning data. In: Power JA, Coombs ML, Freymueller JT (eds) The 2006 eruption of Augustine Volcano, Alaska U. S. Geological Survey Professional Paper 176

McNutt S, Thompson G, West M, Fee D, Stihler S, Clark E (2013) Local seismic and infrasound observations of the 2009 explosive eruptions of Redoubt Volcano, Alaska. J Volcanol Geotherm Res 259:63-76

Nakamichi H, Yamanaka Y, Terakawa T, Horikawa S, Okuda T, Yamazaki F (2013) Continuous long-term array analysis of seismic records observed during the 2011 Shinmoedake eruption activity of 
Kirishima volcano, southwest Japan. Earth Planets Space 65:551562

Neuberg J, Pointer T (2000) Effects of volcano topography on seismic broad-band waveforms. Geophys J Int 143:239-248

Ohlendorf SJ, Thurber CH, Pesicek JD, Prejean SG (2014) Seismicity and seismic structure at Okmok Volcano, Alaska. J Volcanol Geotherm Res 278:63-76

Paulssen H, Levshin AL, Lander AV, Snieder R (1990) Time- and frequency-dependent polarization analysis: anomalous surface wave observations in Iberia. Geophys J Int 103:483-496

Prejean SG, Brodsky EE (2011) Volcanic plume height measured by seismic waves based on a mechanical model. J Geophys Res 116: B01306

Schneider D, Van Eaton A, Mastin L, Wallace K (2020) Satellite observations of the 2016-2017 eruption of Bogoslof volcano: aviation and ash fallout hazard implications from a water-rich eruption. Bull Volcanol (part of the Bogoslof Topical Collection)

Searcy CK, Power JA (2020) Seismic character and progression of explosive activity during the 2016-2017 eruption of Bogoslof volcano, Alaska. Bull Volcanol 82:12. https://doi.org/10.1007/s00445019-1343-4

Soubestre J, Shapiro NM, Seydoux L, de Rosny J, Droznin DV, Droznina SY, Senyukov S, Gordeev EI (2018) Network-based detection and classification of seismovolcanic tremors: example from the Klyuchevskoy volcanic group in Kamchatka. J Geophys Res Solid Earth 123:564-582

Tepp G, Haney MM (2019) Comparison of short-term seismic precursors and explosion parameters during the 2016-2017 Bogoslof eruption. Bull Volcanol 81:63. https://doi.org/10.1007/s00445-019-1323-8
Tepp G, Dziak RP, Haney MM, Lyons JJ, Searcy C, Matsumoto H, Haxel J (2020) Seismic and hydroacoustic observations of the 2016-17 Bogoslof eruption. Bull Volcanol 82:4. https://doi.org/10.1007/ s00445-019-1344-3

Thompson G, McNutt SR, Tytgat G (2002) Three distinct regimes of volcanic tremor associated with the eruption of Shishaldin Volcano, Alaska 1999. Bull Volcanol 64:535-547

Tupper A, Textor C, Herzog M, Graf HF, Richards MS (2009) Tall clouds from small eruptions: the sensitivity of eruption height and fine ash content to tropospheric instability. Nat Hazards 51(2):375-401

Vidale JE (1986) Complex polarization analysis of particle motion. Bull Seismol Soc Am 76(5):1393-1405

Waythomas CF, Angeli K, Wessels R (2020) Evolution of the submarinesubaerial edifice of Bogoslof volcano, Alaska, during its 2016-2017 eruption based on analysis of satellite imagery. Bull Volcanol (part of the Bogoslof Topical Collection)

Wech AG, Creager KC (2007) Cascadia tremor polarization evidence for plate interface slip. Geophys Res Lett 34:L22306

Wech A, Tepp G, Lyons J, Haney M (2018) Using earthquakes, T waves, and infrasound to investigate the eruption of Bogoslof volcano, Alaska. Geophys Res Lett 45:6918-6925. https://doi.org/10.1029/ 2018GL078457

Wegler U, Seidl D (1997) Kinematic parameters of the tremor wavefield at Mt. Etna (Sicily). Geophys Res Lett 24(7):759-762

Welch PD (1967) The use of the fast Fourier transform for the estimation of power spectra: a method based on time averaging over short, modified periodograms. IEEE Trans Audio Electroacoust AU-15:70-73 